\title{
Multicystic encephalomalacia as an end-stage finding in abusive head trauma
}

\author{
S. E. Matlung • R. A. C. Bilo $\cdot$ B. Kubat \\ R. R. van Rijn
}

Accepted: 20 February 2011/Published online: 26 April 2011

(C) The Author(s) 2011. This article is published with open access at Springerlink.com

\begin{abstract}
Abusive head trauma (AHT) is one of the most severe forms of physical child abuse. If a child initially survives severe AHT the neurological outcome can be poor. In recent years several children were seen who developed multicystic encephalomalacia (MCE) after documented severe AHT. A search of the Netherlands Forensic Institute database in The Hague was performed. Inclusion criteria were cases of AHT between 1999 and 2010 where the child was under the age of 1 year old at the time of trauma. Trauma mechanism and radiological information were collected. Five children, three boys and two girls (mean age 57 days, range 8-142 days) who developed cystic encephalomalacia after inflicted traumatic brain injury were included. Survival ranged from 27 to 993 days. In all cases judicial autopsy was performed. All cases came before court and in each case child abuse was considered to be proven. In two cases the perpetrator confessed, during police interrogation, to shaking of the child only. Although a known serious outcome, this is one
\end{abstract}

S. E. Matlung

Faculty of Science, University of Amsterdam, Amsterdam, The Netherlands

R. A. C. Bilo · R. R. van Rijn

Section Forensic Pediatrics, Department of Forensic Medicine, Netherlands Forensic Institute, The Hague, The Netherlands

B. Kubat

Department of Forensic Medicine, Netherlands Forensic Institute, The Hague, The Netherlands

R. R. van Rijn ( $\square)$

Department of Radiology, Academic Medical Centre

Amsterdam, Meibergdreef 9, 1105 AZ Amsterdam, Zuid-Oost,

The Netherlands

e-mail: r.r.vanrijn@amc.uva.nl of the few reports on MCE as a result of AHT. In all cases the diagnosis was confirmed at autopsy.

Keywords Multicystic encephalomalacia - Abusive head trauma $\cdot$ Blunt cerebral injury $\cdot$ Shaking $\cdot$ Impact

\section{Introduction}

The true incidence and prevalence of child abuse is unknown. The reason for this is that in nearly every study trying to establish the incidence and prevalence, researchers use their own definition. Most often this is a 'broad definition', such as that of the World Health Organization (WHO): 'Child abuse, sometimes referred to as child abuse and neglect, includes all forms of physical and emotional ill-treatment, sexual abuse, neglect, and exploitation that results in actual or potential harm to the child's health, development or dignity. Within this broad definition, five subtypes can be distinguishedphysical abuse; sexual abuse; neglect and negligent treatment; emotional abuse; and exploitation'.

A specific form of child abuse which can lead to serious damage, including death, is abusive head trauma (AHT). The group that is most susceptible to AHT are children under the age of 1 year. In two studies, performed in Scotland and the United States, the incidence of severe and fatal AHT was respectively 24.6 and 30 infants per 100,000 children per year [1]. There have been several studies in which parental shaking as a method of discipline were evaluated; in a Dutch study among parents of 3,259 infants, aged 1-6 months, 5.6\% (95\% CI 4.2-7.0\%) of parents reported having smothered, slapped or shaken their child at least one time because of crying [2]. An American study showed that shaking occurred in $2.6 \%$ of children under the age of 2 years [3]. In this study, it was estimated that for 
every 1 child with severe injuries after AHT 150 children suffer AHT without clinical sequela. In a study on nearly 230,000 children in North Carolina it was shown that 29.7 (95\% CI 22.9-36.7) children per 100,000 person years suffered from AHT [1].

The terminology AHT as well as Abuse Head Trauma (AHD) are currently seen as a more appropriate compared to the widely used terminologies of the shaken baby syndrome, the whiplash shaken baby and shaken-impact syndrome. Although these terms all more or less indicate the same clinical entity, AHT and AHD cover all forms of inflicted brain injury irrespective of the underlying mechanisms.

If a child initially survives severe AHT the neurological outcome can be poor. In recent years several children were seen who after documented severe AHT developed multicystic encephalomalacia (MCE).

MCE is an increasingly rare but well documented finding in premature neonates that occurs almost exclusively in premature neonates and is not seen at an older age [4]. Although initially believed to be a result from a cerebrovascular accident (CVA), it is becoming clearer that the development of brain injury in these children is more complex and consists of destructive and developmental disturbances [5].

\section{Materials and methods}

A search of the Netherlands Forensic Institute database in The Hague was performed. Criteria were cases of AHT between 1999 and 2010. The children had to be under the age of 1 year old at the time of trauma. Explanations for the trauma and radiological information from the time of admittance were collected from the database and the police records. Autopsies had been perfomed in all cases and provided pathological proof of MCE.

\section{Results}

A total of five cases of histologically proven MCE were found in the NFI patient database. Patient characteristics are shown in Table 1. The five cases are summarized below.

\section{Cases \\ Case 1}

\section{Clinical history}

A two-month-old girl was admitted to a pediatric university hospital because of convulsions (Table 1). Twenty days
Table 1 Patient characteristics

\begin{tabular}{llrlcll}
\hline Case & Sex & AT $^{\mathrm{a}}$ & EMV $^{\mathrm{b}}$ & Survival $^{\mathrm{c}}$ & AHT & $\begin{array}{l}\text { Suspected } \\
\text { mechanism }^{\mathrm{d}}\end{array}$ \\
\hline 1 & Female & 65 & NR $^{\mathrm{e}}$ & 99 & Proven & Shaking only \\
2 & Male & 142 & $1-1-\mathrm{T}$ & 993 & Proven & Not provided \\
3 & Male & 52 & $1-1-1$ & 333 & Proven & Shaking only \\
4 & Female & 8 & $1-1-\mathrm{T}$ & 27 & Proven & Impact trauma \\
5 & Male & 20 & $\mathrm{NR}$ & 443 & Proven & Not provided \\
\hline
\end{tabular}

a Age at trauma (in days)

b At admission to the emergency department (Glascow coma scale). $T$ tube

c In days

d Based on police interviews

e Not reported

prior to admission she was seen by her local doctor because of a 1st to 2 nd degree burn of the chest $(<10 \%$ total body surface). According to the caregivers this resulted from a leaking bottle cap. Although the pattern could be consistent with this explanation there was a delay in presentation at that time which, in retrospect, should have warranted further evaluation.

On admission cranial ultrasonography showed diffuse hyperechogeneity of the brain parenchyma with increased demarcation of the white matter-cortical border; flow reversal as a sign of increased cranial pressure was also seen (Fig. 1). Computed tomography performed 1 day after admission showed diffuse severe ischemic brain injury

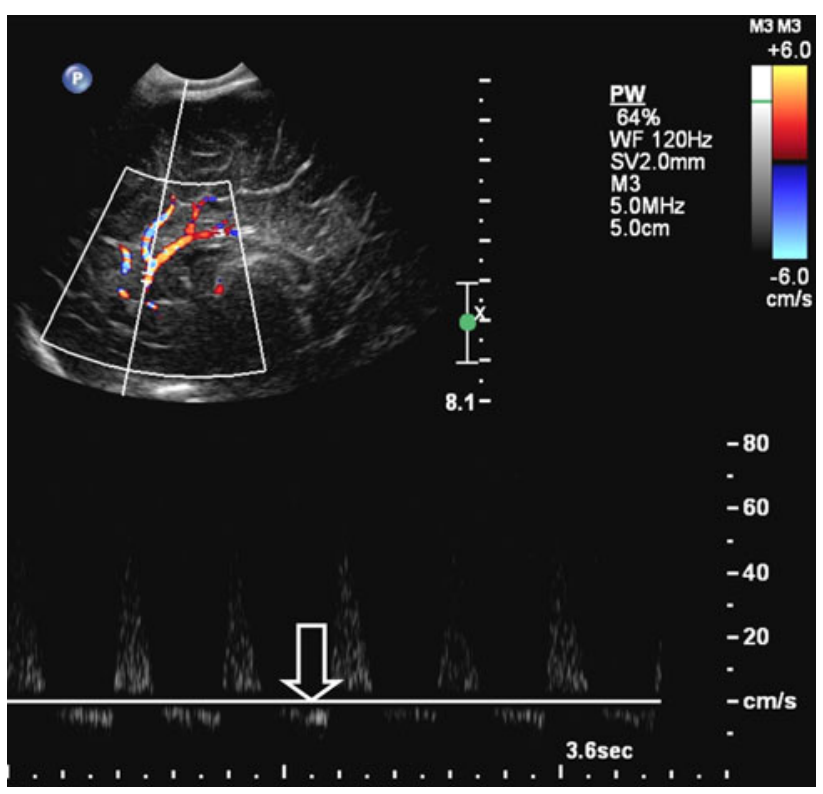

Fig. 1 Cranial ultrasonography showed diffuse hyperechogeneity of the brain parenchyma with increased demarcation of the white matter-cortical border. Doppler US of the pericallosal artery shows diastolic flow reversal as a result of increased intracranial pressure 


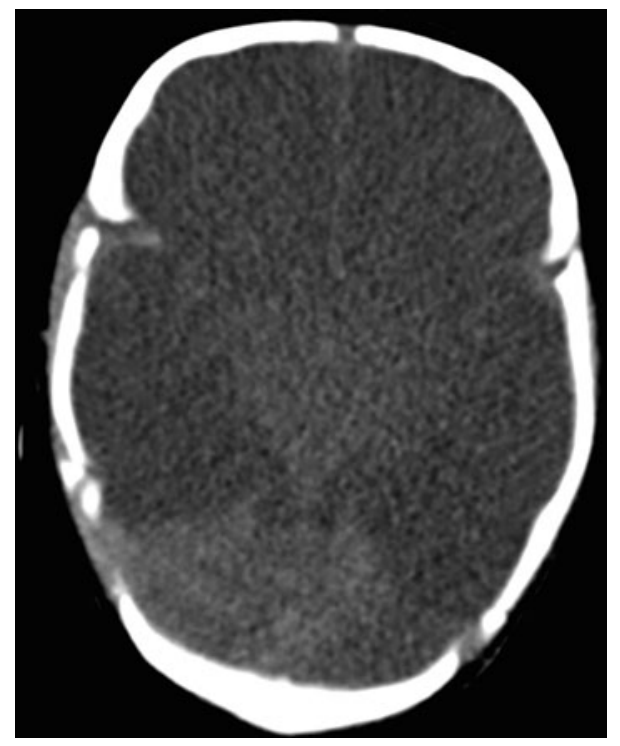

Fig. 2 Computed tomography showed diffuse severe ischemic brain injury with a white cerebellar sign

(Fig. 2). Skeletal survey findings are shown in Table 2. Fundoscopy showed bilateral intra- and pre-retinal hemorrhages. MRI on day 7 showed a post-anoxic brain with a subdural hematoma. A subsequent MRI performed on day 38 showed MCE (Fig. 3).

The clinical, ophthalmological and radiological findings were all highly suggestive of AHT. The girl died at the age of five-and-a-half months, and as the death was related to child abuse a judicial autopsy was performed.

\section{Autopsy}

Neuropathological examination of the brain and the spinal cord revealed a unilateral, several month old

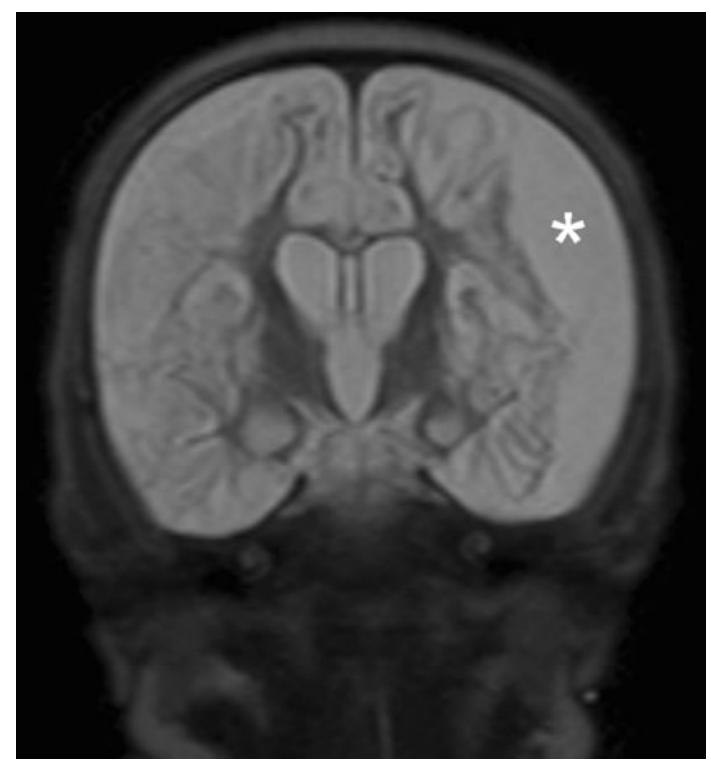

Fig. 3 Coronal T2 weighted MRI shows a subdural left sided effusion (asterisk) and diffuse cystic changes of the brain in keeping with multicystic encephalomalacia

neo-membrane, consistent with an old subdural hematoma. The neo-membrane showed complete organization with moderately cellular connective tissue, normal size blood vessels and extensive iron deposits. There was evidence of several small recent rebleedings in the neo-membrane as well. The brain was extremely atrophic, weighing $200 \mathrm{~g}$ (normal weight for age approximately $490 \mathrm{~g}$ ) [6]. Atrophy was due to a diffuse loss of the cerebral cortical neurons and mainly subcortical necrosis of the white matter. In these areas small to medium sized cavitations occurred (Table 3). The deep white matter revealed extensive reactive gliosis but no cavitation. The ventricular system was moderately

Table 2 Radiological findings

\begin{tabular}{|c|c|c|c|}
\hline Case & Skeletal survey & CT & MRI \\
\hline 1 & $\begin{array}{l}\text { Presentation: } \mathrm{CML}^{\mathrm{a}} \text { distal tibia left } \\
\text { and right }\end{array}$ & $\begin{array}{l}\text { Presentation: Severe ischemic brain injury } \\
\text { SDH Herniation of brain }\end{array}$ & $\begin{array}{l}\text { Presentation: Severe hypoxic brain injury } \\
\text { Demise: Cystic encephalomalacia }\end{array}$ \\
\hline 2 & Presentation: No fractures & $\begin{array}{l}\text { Presentation: Disturbed brain perfusion, } \\
\text { SDH }\end{array}$ & $\begin{array}{l}\text { Presentation: Severe hypoxic brain injury } \\
\text { At follow-up: Development of cystic } \\
\text { encephalomalacia }\end{array}$ \\
\hline 3 & $\begin{array}{l}\text { Presentation: Posterior rib fracture } \\
(6 \text { \& } 7 \text { right })\end{array}$ & Presentation: SDH & Presentation: Ischemic brain injury \\
\hline 4 & Presentation: Fracture roof left orbit & $\begin{array}{l}\text { Presentation: Severe ischemic brain injury, } \\
\text { SDH }\end{array}$ & Not performed \\
\hline 5 & $\begin{array}{l}\text { Presentation: Posterior rib fracture } \\
\text { ( } 7 \text { right) } \\
\text { Oblique femur fracture left } \\
\text { CML distal tibia left and right } \\
\text { Fracture metatarsal I left foot }\end{array}$ & $\begin{array}{l}\text { Presentation: Bilateral subdural } \\
\text { hematomas } \\
\text { Parenchymous hemorrhages } \\
\text { Demise: Hydrocephalus }\end{array}$ & Not performed \\
\hline
\end{tabular}

\footnotetext{
${ }^{a} C M L$ classic metaphyseal lesion
} 
Table 3 Geographic distribution of multicystic encephalomalacia

\begin{tabular}{|c|c|c|c|c|c|c|c|c|c|c|c|c|}
\hline \multirow[t]{2}{*}{ Case } & \multicolumn{2}{|c|}{ Frontal } & \multicolumn{2}{|c|}{ Temporal } & \multicolumn{2}{|c|}{ Parietal } & \multicolumn{2}{|c|}{ Occipital } & \multicolumn{2}{|c|}{ Basal ganglia } & \multicolumn{2}{|c|}{ Cerebelum } \\
\hline & Left & Right & Left & Right & Left & Right & Left & Right & Left & Right & Left & Right \\
\hline 1 & $X$ & $X$ & $X$ & $X$ & $X$ & $X$ & $X$ & $X$ & & & & \\
\hline 2 & $X$ & $X$ & $X$ & $X$ & $X$ & $X$ & $X$ & $X$ & $\mathrm{X}^{\mathrm{a}}$ & $X$ & & \\
\hline 3 & $X$ & $X$ & $X$ & $X$ & $X$ & $X$ & $\mathrm{X}$ & $\mathrm{X}$ & & & & \\
\hline 4 & $X$ & $X$ & $X$ & $X$ & $X$ & $X$ & $X$ & $X$ & & & & \\
\hline 5 & $X$ & $X$ & $X$ & $X$ & $X$ & $X$ & & & & & & \\
\hline
\end{tabular}

${ }^{\text {a }}$ Involvement of caudate nucleus

enlarged. The cerebellum was less affected; loss of the Purkinje cells and the small neurons of the granular layer were observed in the depths of the cerebellar folia, whereas more superficially neurons were mainly spared. The brainstem and the spinal cord showed no major abnormalities apart from secondary degeneration of the corticospinal tracts due to the loss of cortical motor neurons.

\section{Conclusion}

Severe MCE was considered to be related to a generalized hypoxic accident which must have occurred several months prior to the patient's demise. The cause of death was ruled as a result of brain dysfunction.

\section{Case 2}

\section{Clinical history}

A four-month-old boy was admitted to a pediatric university hospital (Table 1). According to the parents he suddenly became unresponsive during feeding.

On admission computed tomography showed a subdural hematoma near the falx cerebri (Fig. 4). Skeletal survey findings are shown in Table 2. Fundoscopy showed bilateral retinal hemorrhages and right-sided pre-retinal hemorrhages. There were no bruises or other visible lesions at admission. CT on day 2 of admission showed again the subdural hematoma, but also signs of a disturbed flow posteriorly. MRI on day 4 showed signs of severe of cerebral hypoxia and multicystic encephalomalacia (Fig. 5). A subsequent MRI, performed on day 17 confirmed multicystic encephalomalacia. He died at the age of 3 years.

\section{Autopsy}

The neuropathological examination revealed a partly hyalinised, unilateral neo-membrane consistent with an at least 12-months-old subdural hematoma. The brain was atrophic (weight $480 \mathrm{~g}$-normal for age approximately 1,140 g).

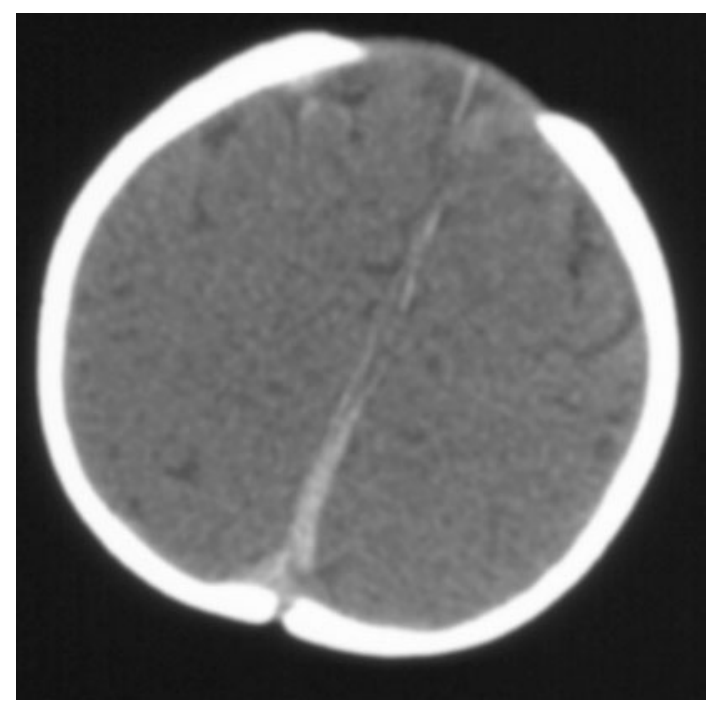

Fig. 4 Computed tomography shows a subdural hematoma along the falx cerebri (arrow)

The cerebral hemispheres and the cerebellum showed loss of almost all neurons in the cortex as well as in the subcortical cerebral and cerebellar nuclei. The cerebral hemispheres showed multiple small cysts in the subcortical white matter of the frontal, temporal and parietal lobes and in the subcortical and deeper parts of the white matter of the occipital lobes (Fig. 6). The ventricular system was significantly dilated. The brainstem revealed loss of neurons in the brainstem nuclei, mineralization of neuronal bodies and capillaries, small cavitations around the aqueduct and the fourth ventricle and secondary degeneration of the long tracts due to the loss of the cortical nuclei.

Histological examination of the eyes showed iron deposits in both eyes, anteriorly as well as posteriorly. Both eyes also showed atrophy of the retina.

\section{Conclusion}

The boy died as a result of an infection, clinically most likely a pulmonary infection although at autopsy no signs of a pulmonary infection were seen. 
Fig. 5 Diffusion weighted MRI (a: DWI and b: ADC) shows restricted diffusion in keeping with cytotoxic edema as a result of hypoxia

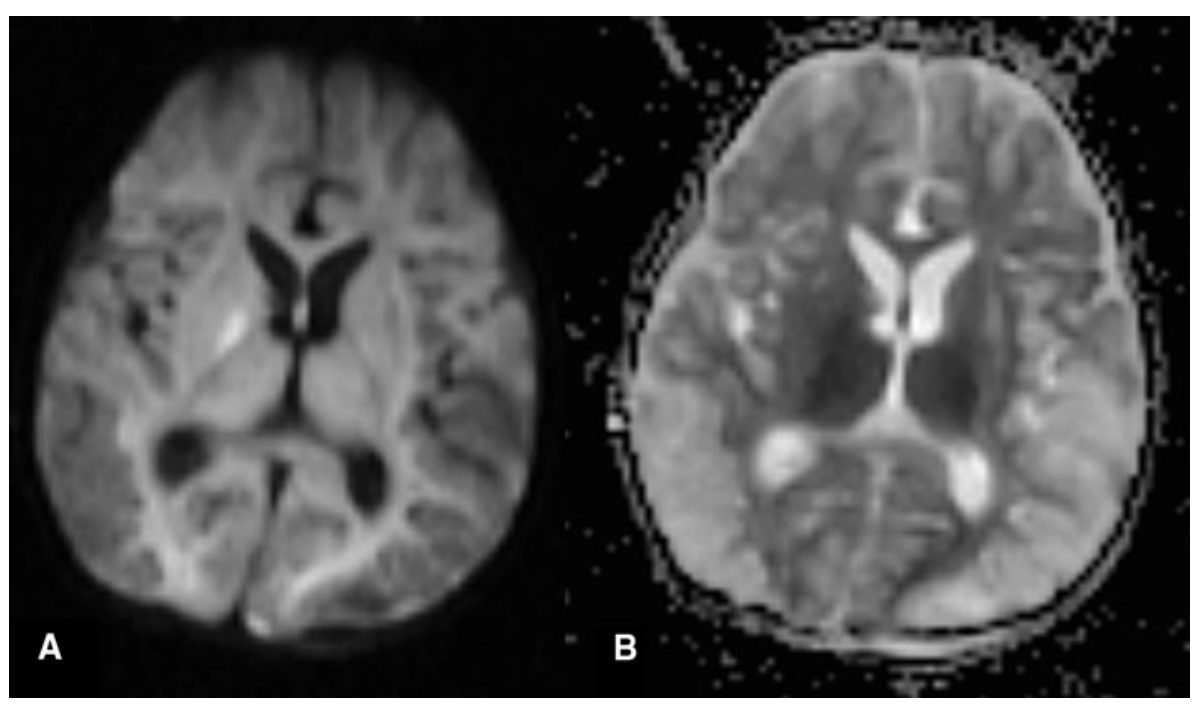

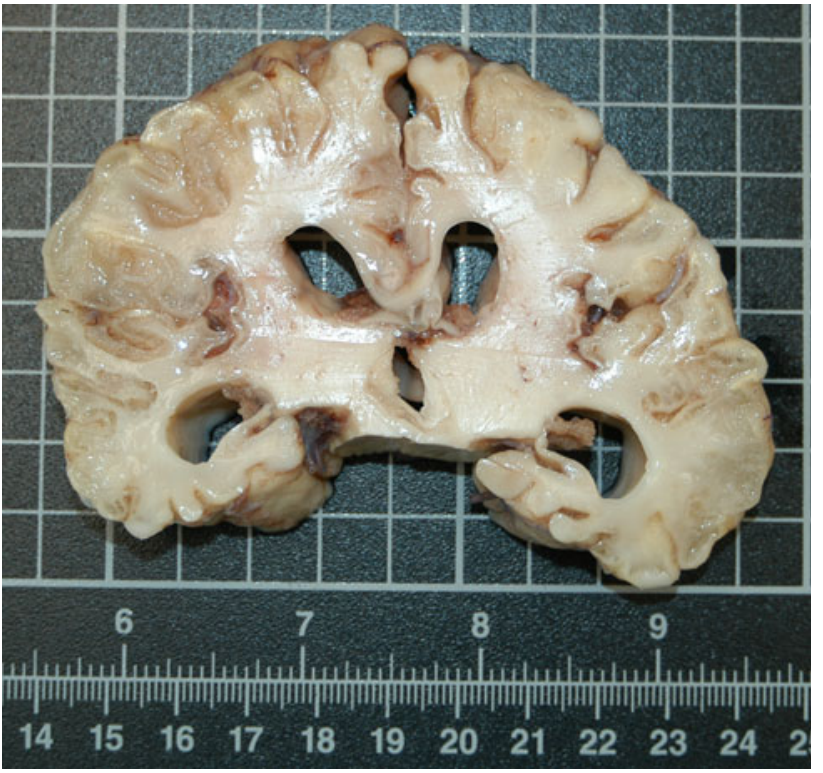

Fig. 6 Gross pathology specimen, coronal section, shows diffuse subcortical necrosis and cystic encephalopathy

\section{Case 3}

\section{Clinical history}

A six-week-old boy presented to an outpatient clinic because of increasing head circumference. Ultrasound showed benign enlargement of the subarachnoid space (BESS) (Table 1). One day later the child was found unresponsive and resuscitation was performed. At admission a bruise on the right side of the face was seen. CT, performed upon admission in a pediatric university hospital, showed wide a subarachnoid space with signs of subarachnoid hemorrhage (Fig. 7). MRI performed 2 days after admission showed diffuse cerebral atrophy, abnormal white matter signal intensity and bilateral subdural

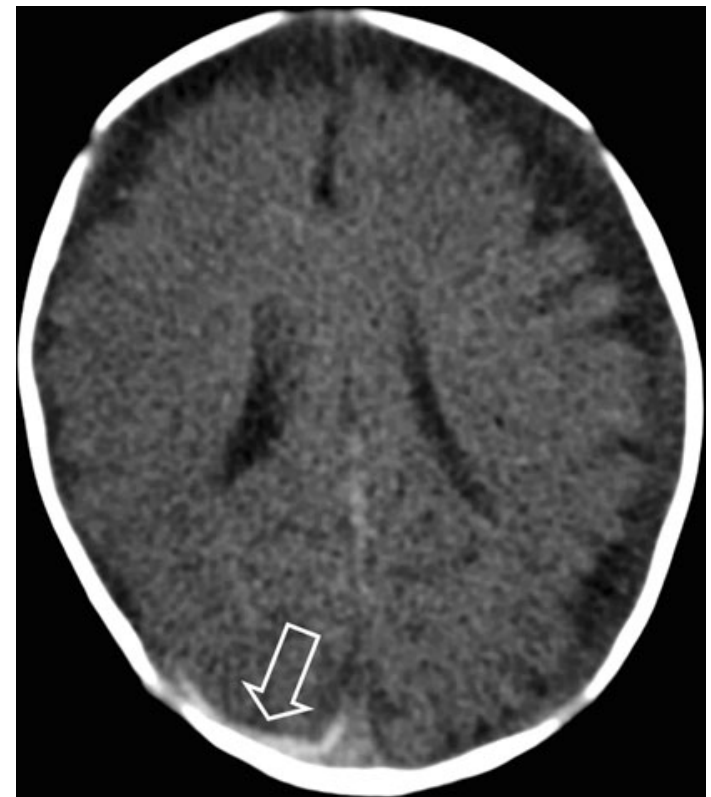

Fig. 7 CT shows wide subarachnoid spaces and a right occipital subdural hematoma (arrow)

hematomas. Fundoscopy showed no retinal hemorrhages. On skeletal survey fractures of the sixth and seventh rib were seen (Table 2).

The boy remained in a permanent vegetative state and more than one year after the initial incident died. As child abuse was the cause of the initial incident, a judicial autopsy was performed.

\section{Autopsy}

The neuropathological examination showed a bilateral, at least several months old, neo-membrane of collagenized connective tissue with normal sized capillaries, iron 
deposits and small recent hemorrhages. The brain was atrophic weighing about half of normal (430 g-normal weight approximately $925 \mathrm{~g}$ ). Microscopy of the basal ganglia showed total loss of cortical and subcortical cerebral neurons, diffuse reactive gliosis, atrophy of the subcortex and subcortical small to medium-sized cavities mostly in the frontal and temporal lobes. There was a large cavum septum pellucidum and significant enlargement of the lateral and the third ventricle. The cerebellum showed patchy degeneration of the cortical neurons with remaining neurons on the outers sections of some cerebellar folia. In the brainstem degeneration of the olivary neurons was found with other nuclei showed varying degrees of neuronal loss. The spinal cord revealed secondary degeneration of the long tracts.

Histological examination of the eyes showed no iron deposits in either eye.

\section{Conclusion}

The cause of death was ruled to be the result of a pulmonary infection in combination with a poor clinical condition, resulting from the initial AHT.

\section{Case 4}

\section{Clinical history}

A seven-day-old girl was found unresponsive in bed. Upon emergency transport to a pediatric university hospital she was intubated with a Glasgow coma scale of E1M1Vtube (Table 1).

CT scan showed diffuse cerebral ischemia, white cerebellar sign, both a subdural and subarachnoid hematoma, and a fracture of the left orbit (Fig. 8). Skeletal survey findings are shown in Table 2. Fundoscopy was normal without signs of retinal hemorrhage.

As the clinical and radiological findings were inconsistent with the presented history AHT was suspected. Although eventually AHT was proven in this case no prosecution could be started as the perpetrator could not be identified. On day 27 after the incident the child suffered brain death.

\section{Autopsy}

The neuropathological examination showed a few-weeks old neo-membrane of cellular, discretely collagenized connective tissue with small capillarys. On the arachnoid surface of the neo-membrane was located an at most few days old blood clot consisting of erythrocytes and few fibroblasts on the dural surface. There was recent subarachnoid hemorrhage on the poles of both temporal lobes.

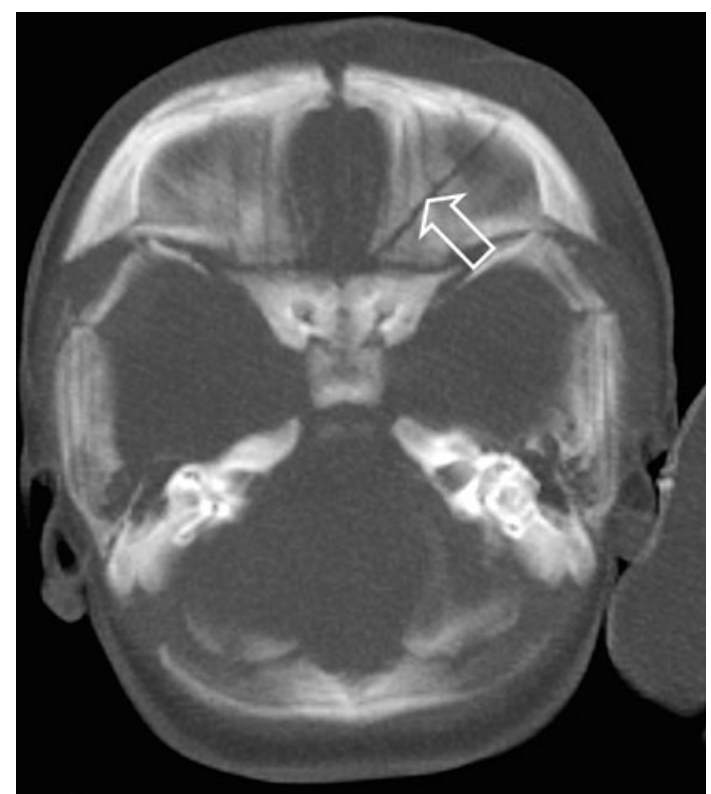

Fig. 8 CT shows a fracture of the left orbit (arrow) as a result of impact trauma

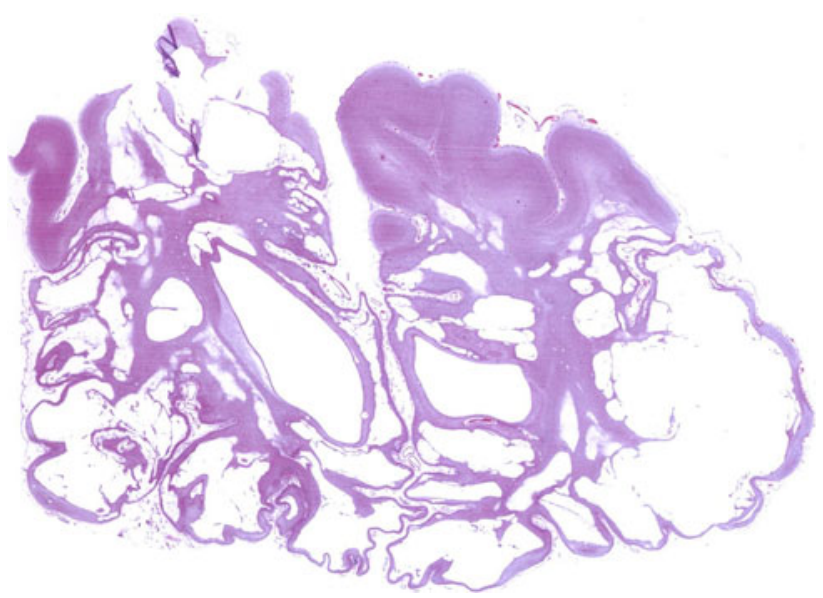

Fig. 9 Coronal microscopic preparation of cerebral hemispheres (HE-stain). The preparation shows multiple diffuse cystic changes in keeping with cystic encephalomalacia

The brain was atrophic (weight $330 \mathrm{~g}$-normal weight for age approximately $490 \mathrm{~g}$ ). The cerebral hemispheres consisted of multiple, mainly large cysts covered only by remnants of the molecular layer of the cortex and extending into the whole subcortex (Fig. 9). Only several gyri of the parietal lobe showed extensive gliosis, loss of the cortical neurons but no cavitation. There was mineralization of parts of the scar tissue and extreme distension of the ventricular system. The cerebellum and the brain stem were spared and revealed normal architecture and no substantial cell loss. The spinal cord showed secondary degeneration of the corticospinal tracts. 


\section{Conclusion}

The cause of death was ruled to be general brain dysfunction as a result of previously sustained trauma.

\section{Case 5}

\section{Clinical history}

A fifteen-month-old boy suffered AHT at the age of 3 weeks. At that time imaging showed subarachnoid, subdural and intraparenchymal hemorrhages. Fundoscopy showed bilateral retinal hemorrhages. Skeletal survey findings are shown in Table 2. A shaking incident was admitted by the father (Table 1 ).

After the incident the child had severe long term complications: hydrocephalus (for which a ventriculoperitoneal shunt, VPD, was inserted), failure-to-thrive for which a percutaneous gastrostomy was inserted, and severe epilepsy. Several days prior to his demise his clinical situation deteriorated severely. Post mortem CT showed hydrocephalus and multicystic encephalomalacia (Fig. 10).

\section{Autopsy}

The neuropathological examination revealed an acute bacterial meningitis and ventriculitis. There were no signs of extension of the infection into the brain parenchyma. The dura showed a patchy, acute inflammatory infiltrate. Distinct subdural hemorrhage was not found in the examined parts of the dura, although there were some intradural iron deposits. The cerebral hemispheres showed extensive

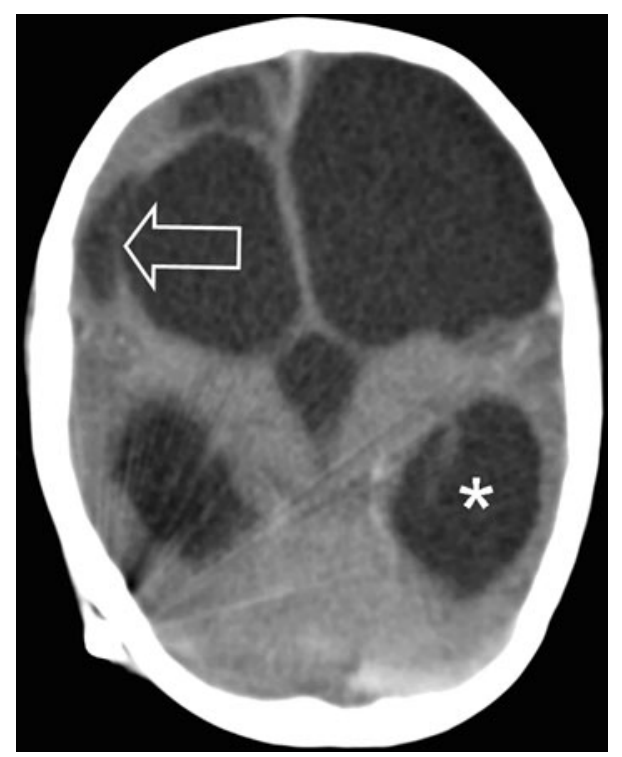

Fig. 10 Post mortem CT shows hydrocephalus (asterisk) and multicystic encephalomalacia (arrow) loss of cortical and subcortical neurons and in part asymmetrical atrophy of the white matter, with small and larger cavities especially in the left cerebral hemisphere. The cerebellum revealed irregular loss of neurons predominantly in the depths of the cerebellar folia with reactive glial changes and no cavitation. The dentate nucleus, the brain stem and the spinal cord showed no neuronal loss; there was a secondary degeneration of the long tracts due to the loss of cortical neurons.

Histological examination of the eyes showed iron deposits in both eyes.

\section{Conclusion}

Purulent meningitis was ruled to be the cause of death.

\section{Discussion}

Subdural hematomas (SDH) were present in all cases. The radiological signs, together with other information, such as clinical evaluation, parental history and fundoscopy, raised the suspicion of AHT. In view of the clinical evaluation we postulate that in our cases MCE was not caused by perinatal trauma but by AHT.

AHT, which includes both shaking only, shaking-impact and impact only trauma, is highly associated with SDH, but the findings are not pathognomonic [7]. Severe trauma, e.g. a motor vehicle accident, can mimic the mechanism and clinical findings seen in AHT [8]. Furthermore coexistent bleeding disorders might make an infant more vulnerable for developing SDH [7]. Underlying diseases, e.g. Glutaric aciduria type 1 , hase to be ruled out before diagnosing AHT [9, 10].

As stated above, the shaking-impact mechanism in AHT is generally accepted as a cause of SDH. The accelerationdeceleration process of the brain during shaking, described by Caffey, causes rupturing of vulnerable veins, which are bridging between the two membranes [11]. This causes bleeding into the subdural space. Intracranial hemorrhage is a space-occupying process, in severe cases which can lead to ischemic brain injury. Even in cases where the SDH is not severe enough to cause a space-occupying process ischemic brain injury can be seen, we therefore assume that this is caused by generalized edema of the brain [12]. Ischemic brain injury can also be caused by cardiac or respiratory failure, this is mostly seen in patients after the perinatal period [12]. It is suggested that hypoxic ischemic events can cause MCE in patients and that it is mostly seen in infants after severe asphyxia.

As shown above, five children were diagnosed with MCE from our database search from 2001. In all our cases AHT was proven and the absence of MCE on initial imaging indicates that MCE developed as a result of AHT. 
MCE is mostly seen in infants after a perinatal period of severe asphyxia and this hypoxic-ischemic event is the generally accepted major cause of MCE. In general, hypoxic brain events have four major causes:

1. Disturbed oxygen uptake in blood leading to oxygenation of tissue (including the brain). This can for example be seen in cases of carbon-monoxide poisoning.

2. Disturbance of blood circulation to the brain as a result of a systemic disturbed blood flow. This can be seen in cases of hypovolemic shock.

3. Disturbance of blood circulation to the brain as a result of compression of the vasculature of the head and neck. This can be seen in cases of strangulation.

4. Diffuse brain edema leading to a rise in intracranial pressure leading to hypoperfusion of the brain. This can be seen in case of neurotrauma such as MVA and AHT.

MCE has a poor prognosis in neonates, especially when the neonate is persistently hypotonic after birth. Most children die or are severely handicapped [13, 14].

Neonates with MCE due to perinatal trauma show several other changes, including alterations in the basal ganglia and a white cerebellar sign. In our cases, the same alterations were seen which raises the suspicion that they had a hypoxic-ischemic event not caused by perinatal trauma but by AHT.

Another sign seen in all of our children was retinal hemorrhage. Although there are several causes of retinal hemorrhages, it appears in $85 \%$ of the cases with AHT [15]. In cases of AHT especially bilateral retinal bleeding are seen.

SDH and retinal hemorrhages raise high suspicions of AHT due to infant shaking. One of the most striking aspects of this kind of trauma is the absence of external visible signs of trauma. On radiographic examination, (old) rib fractures and metaphysical fractures of the long bones are strong indicators of inflicted injury [16].

In conclusion, MCE after AHT is rare, but has been described [17]. MCE is mostly seen after severe asphyxia during the perinatal period and is thought to be caused by a hypoxic-ischemic event that causes brain damage. After the perinatal period hypoxic-ischemic encephalomalacia is mostly seen after cardiopulmonary arrest [18]. A hypoxicischemic event during AHT may also be the cause of MCE in our experience. In all cases AHT was related with SDH. This can cause an hypoxic-ischemic event, but it has to be severe. In our cases the hypoxic-ischemic events might have caused the development of MCE. Within a week after admission all children developed signs of MCE, as seen on MRI. At autopsy, the brain showed cystic changes in all cases. This confirmed the diagnosis of MCE after AHT.
Our cases were admitted to hospital and developed MCE due to hypoxic-ischemic event related to proven AHT. We have shown that MCE can develop in cases of AHT with a hypoxic-ischemic event from AHT provoking the pathological mechanism behind the development of MCE. It is not clear why some children develop MCE, while others do not.

\section{Key-points}

1. Abusive head trauma can have serious long and short term outcomes.

2. Multicystic encephalopathy can develop in a short time span (27 days after the incident in this study).

3. As confessed by the perpetrator during police interrogation, abusive head trauma can be the result of a shaking incident alone.

Open Access This article is distributed under the terms of the Creative Commons Attribution Noncommercial License which permits any noncommercial use, distribution, and reproduction in any medium, provided the original author(s) and source are credited.

\section{References}

1. Keenan HT, Runyan DK, Marshall SW, et al. A population-based study of inflicted traumatic brain injury in young children. JAMA. 2003;290(5):621-6.

2. Reijneveld SA, van der Wal MF, Brugman E, et al. Infant crying and abuse. Lancet. 2004;364(9442):1340-2.

3. Theodore AD, Chang JJ, Runyan DK, et al. Epidemiologic features of the physical and sexual maltreatment of children in the Carolinas. Pediatrics. 2005;115(3):e331-7.

4. Volpe JJ. Brain injury in premature infants: a complex amalgam of destructive and developmental disturbances. Lancet Neurol. 2009;8(1):110-24.

5. Sie LT, van der Knaap MS, Oosting J, et al. MR patterns of hypoxic-ischemic brain damage after prenatal, perinatal or postnatal asphyxia. Neuropediatrics. 2000;31(3):128-36.

6. Coppoletta JM, Wolbach SB. Body length and organ weights of infants and children: a study of the body length and normal weights of the more important vital organs of the body between birth and twelve years of age. Am J Pathol. 1933;9(1):55-70.

7. Trenchs V, Curcoy AI, Navarro R, et al. Subdural haematomas and physical abuse in the first two years of life. Pediatr Neurosurg. 2007;43(5):352-7.

8. Stoodley N. Controversies in non-accidental head injury in infants. Br J Radiol. 2006;79(943):550-3.

9. Fernando S, Obaldo RE, Walsh IR, et al. Neuroimaging of nonaccidental head trauma: pitfalls and controversies. Pediatr Radiol. 2008;38(8):827-38.

10. Jayawant S, Rawlinson A, Gibbon F, et al. Subdural haemorrhages in infants: population based study. BMJ. 1998;317(7172): 1558-61.

11. Caffey J. The whiplash shaken infant syndrome: manual shaking by the extremities with whiplash-induced intracranial and intraocular bleedings, linked with residual permanent brain damage and mental retardation. Pediatrics. 1974;54(4):396-403. 
12. Oehmichen M, Schleiss D, Pedal I, et al. Shaken baby syndrome: re-examination of diffuse axonal injury as cause of death. Acta Neuropathol. 2008;116(3):317-29.

13. Garten L, Hueseman D, Stoltenburg-Didinger G, et al. Progressive multicystic encephalopathy: is there more than hypoxiaischemia? J Child Neurol. 2007;22(5):645-9.

14. Butefisch C, Edwards D, Schochet SS Jr. Neurological features of perinatal asphyxia: a clinical and pathological study of a neonate with multicystic encephalopathy. Semin Pediatr Neurol. 1996; 3(3):236-42.

15. Case ME. Inflicted traumatic brain injury in infants and young children. Brain Pathol. 2008;18(4):571-82.
16. Lonergan GJ, Baker AM, Morey MK, et al. From the archives of the AFIP. Child abuse: radiologic-pathologic correlation. Radiographics. 2003;23(4):811-45.

17. Marin-Padilla M. Developmental neuropathology and impact of perinatal brain damage. II: white matter lesions of the neocortex. J Neuropathol Exp Neurol. 1997;56(3):219-35.

18. Gutierrez LG, Rovira, A, Portela, LA, et al. CT and MR in nonneonatal hypoxic-ischemic encephalopathy: radiological findings with pathophysiological correlations. Neuroradiology. 2010. 